\title{
Denture barcoding: a new horizon
}

\author{
S. Agüloğlu, ${ }^{1}$ M. Zortuk ${ }^{2}$ and K. Beydemir ${ }^{3}$
}
IN BRIEF
- Denture barcoding can be used with crown and bridge restorations and can survive temperatures above $600^{\circ} \mathrm{C}$, which can be encountered in plane crashes.
- Denture barcoding gives exact information in every situation regardless of whether fire or water are involved.
- Denture barcoding is easy to perform and not very expensive, especially if a special marking device can be improved.

\begin{abstract}
Labelled dentures can be important in identifying people who have lost their memory or in identifying the bodies of those who have died in disasters. Forensic dentistry has long considered marking dentures, although no standardised method has been developed. Of the many options considered, none maintain the marking after the dentures break or are altered in occurrences such as plane crashes, which can result in a marked increase in temperature. This study examined a ceramic marking system that can endure high temperatures and can also be used in fixed partial dentures.
\end{abstract}

\section{NTRODUCTION}

In disasters such as earthquakes, landslides, fires or plane crashes that can result in many deaths or for patients who have lost their memory owing to personal health issues such as Alzheimer's disease, labels on dentures can provide identifying information. ${ }^{1-4}$ Studies have examined this concept before, but no fireproof method has been devised. Previous attempts have focused on removable dentures, but the marking methods have either ruined the denture aesthetics or increased the denture weight, or the flammable or fragile nature of the dentures has rendered them unsuitable for a marking system. To be useful, a marking label for dentures must be easy to apply and inexpensive, must give definite information in every situation, must not alter the structure of the dentures, must not affect denture aesthetics, and must resist high temperatures and fire. ${ }^{1,5,6}$

The ceramic marking technique that we studied is easy to perform and is not very expensive, especially if a special marking

${ }^{1 *}$ Prosthetic Rehabilitation, Dicle University Faculty of Dentistry, Diyarbakır, 21280, Turkey; ${ }^{2}$ Erciyes University, Kayseri, 41445, Turkey; ${ }^{3}$ Dicle University, Diyarbakır, 21280, Turkey

*Correspondence to: Dr Süleyman Agülo lu Email:sagul9127@hotmail.com

\section{Refereed Paper}

Accepted 23 March 2009

DOI: $10.1038 /$ sj.bdj.2009.477

${ }^{\circledR}$ British Dental Journal 2009; 206: 589-590 device can be improved. It gives exact information in every situation regardless of whether fire or water is involved and is aesthetic, as it involves the palatal area of the dentures. In addition, this technique can be used with crown and bridge restorations. A large number of people use fixed or removable dentures, and this technique would be appreciated by many.

\section{TECHNIQUE}

The labelling technique involves printing a number code on paper, photographing the paper and making a negative of the photo, and transferring the negative image to a piece of silk (Fig. 1). The silk is stretched over the rim of the device used to pattern ceramic faience, and a plain piece of white faience $(15 \times 25 \mathrm{~mm})$ is placed beneath the rim (Fig. 2). Then, faience paint containing black ceramic is applied to the negative barcode region on the silk, and a machine forces the paint through the silk, creating an image on the white faience. Finally, the faience is heated to $860^{\circ} \mathrm{C}$ for 30 minutes in an industrial porcelain oven, after which we ensure that the barcode can be read. If the barcode is legible, the faience is ground down to measure $3 \times 5 \times 1 \mathrm{~mm}$ (Fig. 3), placed in a $3.5 \times 5.5 \times 1.5 \mathrm{~mm}$ slot in the removable partial denture (Fig. 4), and sealed using self-curing acrylic resin (Fig. 5). For a fixed prosthesis, a crown is placed under the same device, ceramic paint is transferred, and then the crown is heated and stabilised (Fig. 6).

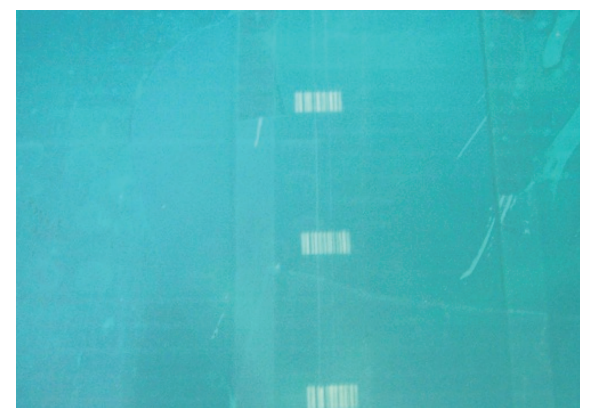

Fig. 1 The negative transfer of the barcode on the silk

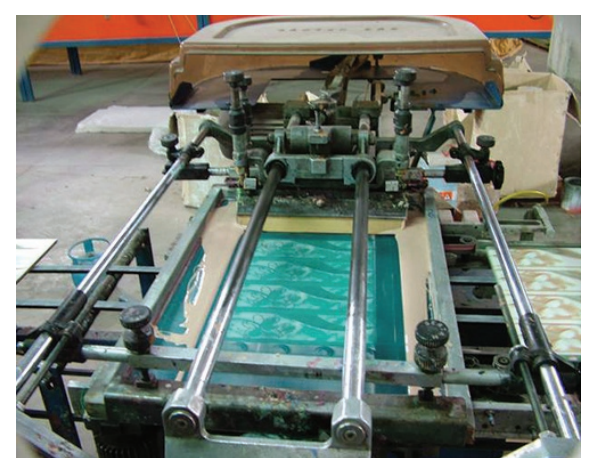

Fig. 2 The pattern device

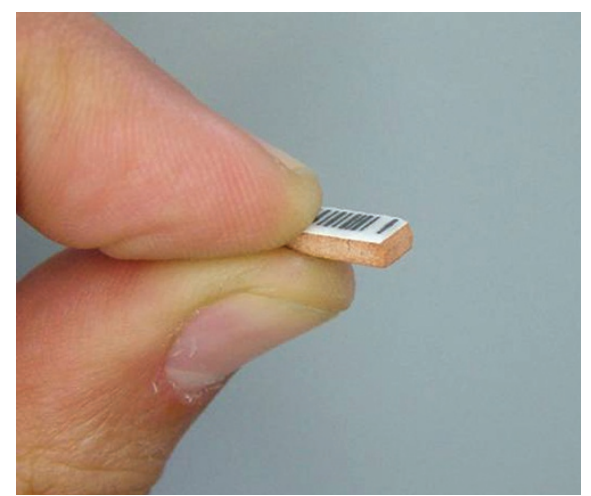

Fig. 3 The barcoded faience piece 


\section{DISCUSSION}

In the 1980s, researchers such as Heath ${ }^{7}$ and Stevenson ${ }^{8}$ proposed different techniques for writing names on removable dentures. In the 1990s, researchers such as Ling, ${ }^{9}$ Furst, ${ }^{10}$ Ibrahim ${ }^{11}$ and Berry ${ }^{12}$ wrote personal information on different materials that were then buried in the acrylic. ID labels became more technological in the 2000s, making use of microchips and radio-frequency devices. In 2002, Rajan and Julian ${ }^{13}$ reported a method based on electronic microchip manufacturing technology. To maximise the amount of data that could be written on a metallic ID label, Ling et $a l .{ }^{14}$ used a high-power copper vapour laser in 2003. In 2004, Millet and Jeanin $^{5}$ implanted a radio-frequency ID transponder in a complete upper denture. Unfortunately, none of these techniques are sufficiently fireproof, and none can be used with fixed partial dentures.

By contrast, markings made using our technique can survive temperatures above $600^{\circ} \mathrm{C}$, which can be encountered in plane crashes, and can be applied to a simple porcelain crown. Markings made on a fixed prosthesis by this technique are not affected by environmental wear such as brushing, solid foods, and polishing, and are not affected unless the porcelain facet breaks down. In addition, because the surface is smooth, bacteria do not accumulate over the label.

We performed this study in a ceramic faience factory under very primitive conditions, and the technique was difficult to perform. With the development of a

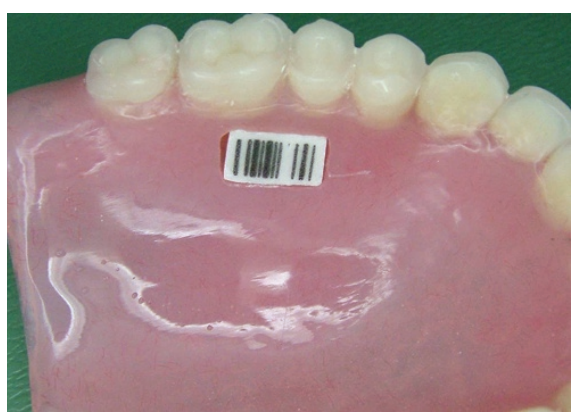

Fig. 4 The barcoded faience piece placed in a $3.5 \times 5.5 \times 1.5 \mathrm{~mm}$ slot

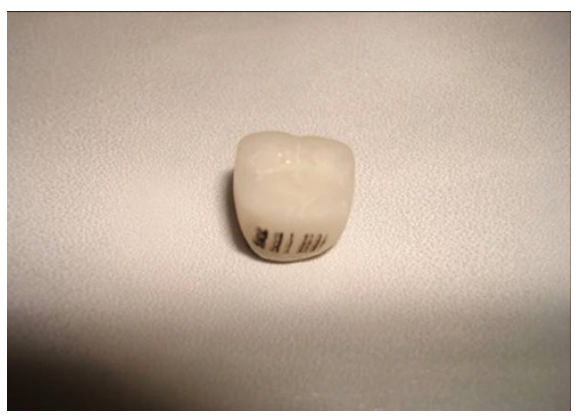

Fig. 6 Barcoded porcelain crown

porcelain labeling device, the technique should become easier and less expensive.

The authors thank the Megaser Faience factory,

Diyarbakır, Turkey and Diser Ceramic factory

Diyarbakir, Turkey.

1. Richmond R, Pretty I A. Contemporary methods of labeling dental prostheses - a review of the literature. J Forensic Sci 2006; 51: 1120-1126.

2. Richmond R. Denture marking in the UK. Br Dent J 2007; 203: 652-653.

3. Reeson M G. A simple and inexpensive inclusion technique for denture identification. J Prosthet Dent 2001; 86: 441-443.

4. Borrman H I, DiZinno J A, Wasén J, René N. On denture marking. J Forensic Odontostomatol 1999; 17: 20-26.

5. Millet $\mathrm{C}$, Jeannin $\mathrm{C}$. Incorporation of microchips to facilitate denture identification by radio frequency tagging. J Prosthet Dent 2004; 92: 588-590.

6. Richmond R, Pretty I A. Denture marking-patient

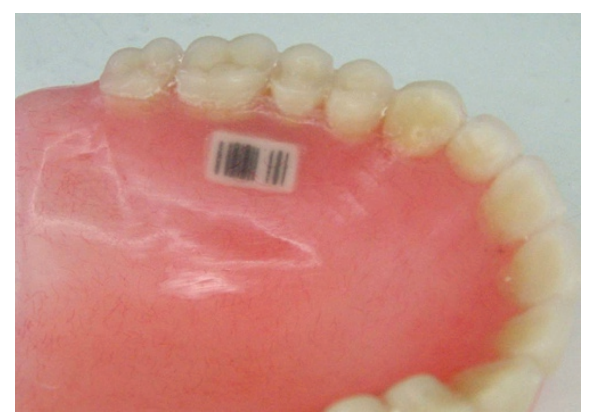

Fig. 5 The barcode sealed using self-curing acrylic resin

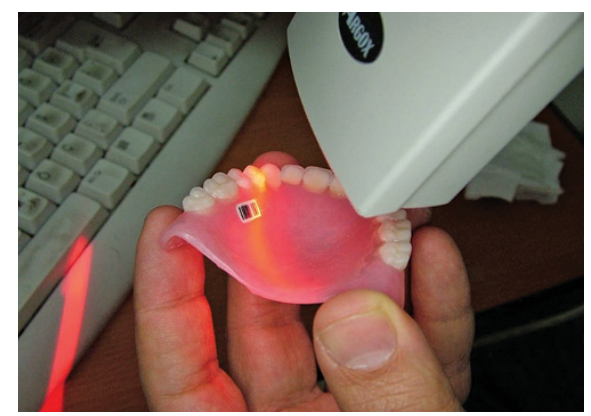

Fig. 7 Reading the barcode

preference of various methods. J Forensic Sci 2007; 52: 1338-1342.

7. Heath J R. Denture identification-a simple approach. J Oral Rehabil 1987; 14: 147-163.

8. Stevenson R B. Marking dentures for identification. J Prosthet Dent 1987; 58: 255-260.

9. Ling B C. A white character denture labelling technique. J Prosthet Dent 1993; 69: 545-547.

10. Furst G. A white character denture labelling technique. J Prosthet Dent 1994; 71: 224-229.

11. Ibrahim W M. Denture microlabeling technique. J Prosthet Dent 1996; 76: 104-107.

12. Berry F A, Logan G I, Plata R, Riegel R. A postfabrication technique for identification of prosthetic devices. J Prosthet Dent 1995; 73: 341-344.

13. Rajan M, Julian R. A new method of marking dentures using microchips. J Forensic Odontostomatol 2002; 20: $1-5$.

14. Ling B C, Nambiar P, Low K S, Lee C K. Copper vapour laser ID labelling on metal dentures and restorations. J Forensic Odontostomatol 2003; 21: 17-22. 